\title{
КАМПАНИИ \\ ПО УПОРЯДОЧЕНИЮ ПОЛЬЗОВАНИЯ СЛУЖЕБНЫМИ АВТОМОБИЛЯМИ В СССР (КОНЕЦ 1950-X-1980-E ГГ.)
}

Статья посвящена проблеме, не являвшейся ранее предметом специального исследования в исторической и социологической литературе,кампаниям по упорядочению пользования служебными автомобилями в СССР в контексте борьбы с привилегиями советского «правящего класса». Исследование подготовлено на базе архивных документов, впервые введенных автором в научный оборот, нормативно-правовых актов, материалов периодической печати, источников личного происхождения. В исследовании автор исходит из признания привилегий для членов партийно-хозяйственной номенклатуры в СССР, носивших «вещный» характер и выражавшихся в том числе в предоставлении части государственного имущества в личное пользование. Основное место уделяется периоду «оттепели», поскольку в конце 1950-х гг. очевидные излишества в материально-бытовом обеспечении номенклатуры впервые стали рассматриваться как социальная проблема. С одной стороны, это обусловливалось пополнением отечественного автопарка; с другойпровозглашением построения общества социальной справедливости. Кампания не прибавила популярности Н.С. Хрущеву в рядах номенклатуры и способствовала его отстранению от власти. В последующие годы все попытки изменить доступ служащих госаппарата к ведомственному транспорту предусматривали мероприятия, опробованные на рубеже 1950-1960-х гг.: передачу машин в автохозяйства общего пользования, уменьшение расходов на содержание служебных машин, использование их без штатных водителей, сокращение парка специальных машин. И ни одна из этих реформ не явилась сколько-нибудь результативной. На примере кампаний по упорядочению пользования ведомственным транспортом в статье рассматривается социальный аспект советской

Елена Дмитриевна Твердюкова - д.и.н., доцент, профессор кафедры новейшей истории России, Институт истории, Санкт-Петербургский государственный университет, СанктПетербург, Россия. Электронная почта: e.tverdyukova@spbu.ru 
автомобилизации. Автор доказывает, что автомобиль в СССР являлся не только средством передвижения, а одним из важнейших элементов социального порядка. Наделенный символической функцией престижности и принадлежности к привилегированному меньшинству, он выступал своеобразным маркером стратификации общества. В этой связи реформирование служебного автопарка было обречено на неудачу и являлось классическим примером попытки реализации политической утопии по достижению социального равенства.

Ключевые слова: СССР, правящий класс, советская номенклатура, привилегии, автомобиль, реформы

DOI: 10.17323/727-0634-2019-17-2-253-266

Деятельность номенклатуры в СССР- одного из важнейших элементов советской властной системы- часто привлекает внимание исследователей (Крыштановская 2005; Пашин, Свириденко 1998; Левин 1997; Коржихина, Фигатнер 1993). Подготовлен ряд работ, посвященных вопросам материального обеспечения номенклатуры (Шалак 2013; Соболев 2012; Кондратьева 2006; Коновалов 2005), но вопросы эволюции льгот и привилегий «правящего класса», в том числе закрепления за руководящими кадрами персональных автомобилей, малоизучены. Как полагает большинство ученых, автомобильная культура в СССР имела отличную от западных стран логику развития: являясь частью советской экономики дефицита, автомобиль выступал гораздо более значимым символом социального статуса (Мирская 2013; Кононенко 2011; Сигельбаум 2011; Siegelbaum 2009). При этом исследователи фокусируются на вопросах, связанных с развитием личного транспорта, принадлежавшего частным владельцам. Практика использования ведомственных машин до сих пор не становилась объектом специального исследования, хотя может дополнить картину социальных иерархий советского общества.

Отсутствие в СССР классического права собственности на средство передвижения (предусматривающего в юридической доктрине возможность владения, пользования и распоряжения) не мешало служащим госаппарата широко пользоваться служебными автомобилями в нерабочее время. В условиях послевоенной автомобилизации страны, когда отечественный автопарк пополнился за счет марок «Москвич» и «Победа», об этом можно говорить как о социальной проблеме. Массовое использование служебных машин для личных целей бюрократов на фоне провозглашения построения общества социальной справедливости приобрело характер, отражающий социальное неравенство, что, очевидно, понимало и руководство страны, предпринявшее попытку пересмсотра сложившихся к тому времени номенклатурных «правил игры».

В этом исследовании под номенклатурой, вслед за Милованом Джиласом, мы понимаем профессиональную партийную бюрократию, пользующуюся 
и распоряжающуюся всей обобществленной собственностью и принимающей решения государственной важности (Джилас 1961:50). В анализе исторических документов мы исходили из признания номенклатурных привилегий в СССР, носивших «вещный» характер и выражавшихся в том числе в предоставлении части государственного имущества в личное пользование. Так, одной из важнейших привилегий как раз и являлось закрепление за представителями номенклатуры персональных машин с шоферами. В Советском Союзе вплоть до середины 1940-х гг. автомобили не поступали в розничную продажу: их можно было ввезти из-за границы, получить в награду в качестве признания высоких государственных заслуг или выиграть в лотерею. Этим легальные возможности приобретения машин исчерпывались. Поэтому владение легковым авто априори предполагало высокий статус его владельца. Учитывая, что большая часть транспортных средств в эти годы была ведомственной, автомобиль символизировал не классовые различия, а близость к власти и положение в новой государственной иерархии.

Указанная проблема изучалась нами на основе не публиковавшихся ранее документов Государственного архива РФ (прежде всего фонд 9477Комиссия государственного контроля Совета Министров СССР, 9527- Комитет народного контроля СССР), Центрального государственного архива Санкт-Петербурга (фонд 7384 - Санкт-Петербургский городской совет народных депутатов, 9626- Ленинградская группа контролеров Комиссии государственного контроля Совета Министров РСФСР), опубликованных записей заседаний Президиума ЦК КПСС, материалов периодической печати, источников личного происхождения.

\section{«От привилегий отказаться»}

На открытии ХХ съезда КПСС 14 февраля 1956 г. Н.С. Хрущев сделал беспрецедентное заявление о необходимости борьбы с «расточительным» использованием чиновниками легковых авто. Он предложил «решительно переходить на социалистические начала в этом деле, ликвидировать практику закрепления машин за отдельными работниками, установив строго ограниченное количество персональных машин» (XX съезд 1956: 51). Таким образом, опровергается предположение составителей сборника «Президиум ЦК КПСС. 1954-1964» о том, что идея радикального изменения порядка пользования «персоналками» с целью значительной экономии финансовых средств могла возникнуть у Н.С. Хрущева во время его визита в США в 1957 г., где практика содержания персонального шофера к тому времени была исключением из общего правила (Фурсенко 2008:969). Первый секретарь считал, что массовое пользование автомобилем- расточительство (трата ресурсов, загрязнение воздуха) и ратовал за развитие городского общественного транспорта, в том числе по той причине, что в нем пассажиры уравнены в правах: нет ни богатых, ни бедных. 
В соответствии с поручением Президиума ЦК КПСС специальная («лимузинная», по выражению С.Н. Хрущева) комиссия рассмотрела проект постановления «О порядке использования легковых автомобилей». $\mathrm{B}$ нем предусматривалась отмена сложившейся практики персонального закрепления служебного транспорта за номенклатурными работниками. Право пользования сохраняли министры СССР и приравненные к ним лица; в союзных республиках - секретари Центральных Комитетов партии, председатели Президиумов Верховных Советов и их заместители, председатели Советов Министров и их заместители; первые секретари крайкомов и обкомов партии, председатели крайисполкомов и облисполкомов, председатели совнархозов, первые секретари горкомов партии и председатели горисполкомов столиц союзных республик. Для Москвы и Ленинграда были приняты специальные нормативные акты. Так, постановление Совета Министров РСФСР 25 декабря 1956 г. разрешало персональное закрепление легковых автомобилей только за руководителями наиболее крупных ленинградских предприятий, учреждений и организаций. Намечалось в течение 1-2 лет упразднить должности штатных шоферов на служебных легковых автомобилях в сельской местности (сельским райкомам партии и райисполкомам разрешалось оставить не более двух штатных единиц на район), имея в виду, что пользовавшиеся машинами работники должны сами управлять транспортным средством.

В марте 1959 г. в министерствах, ведомствах, совнархозах, партийных и советских органах, предприятиях, организациях и учреждениях страны числилось примерно 143 тыс. служебных автомобилей, расходы на их содержание составляли около 2,2 млрд руб. в год, а годовая стоимость содержания (в зависимости от марки и продолжительности работы)- от 18 до 48 тыс. руб. За год автомобиль пробегал в среднем около 25 тыс. километров (Фурсенко 2008:34-35). Для обслуживания деловых поездок номенклатурных работников и доставки служебной корреспонденции предусматривалось сохранение в министерствах и ведомствах 1-2-х дежурных автомобилей, как правило, «Москвич». Другие машины должны были передаваться хозяйствам автомобильного транспорта, как и автобазы, гаражи и авторемонтные мастерские - со всеми товарно-материальными ценностями, оборудованием и материалами. На их основе предполагалось создавать ведомственные хозрасчетные таксомоторные гаражи для обслуживания чиновников с оплатой по тарифам, установленным для такси общего пользования. Чтобы компенсировать затраты, госслужащим, имевшим ранее право персонального пользования легковым автомобилем, выплачивалась 1 тыс. рублей в месяц, а вызывавшим дежурные машины из общего наряда -500 руб. Предполагалось, что эти выплаты обеспечат возможность при пользовании автомобилями «Победа» и «Волга» при действующем тарифе в размере 1 руб. 50 коп. оплачивать 330-660 километров пробега в месяц (или 4-8 тыс. в год). При поездках на автомобиле «Москвич» с более 
дешевым тарифом (1 руб.) покрывалось 6-12 тыс. километров пробега. Намеченные мероприятия могли бы высвободить до 63 тыс. автомобилей, что позволяло сократить расходы на их содержание на сумму свыше 1,2 млрд руб. в год. С учетом денежных выплат работникам, ранее пользовавшимся служебными автомобилями (около 230 млн руб.), ежегодные расходы на содержание «персоналок» должны были сократиться примерно на 970 млн руб. (Фурсенко 2008: 29, 34-35).

Реформу следовало завершить к 1 июня 1959 г. Однако эффект оказался совсем не тот, на который рассчитывало руководство страны. Так, в Московском областном совнархозе в 1960 г. работало на обслуживании аппарата 17 автомобилей с общим пробегом 519680 километров (ГА РФ. Ф. 9477. Оп. 1. Д. 825. Л. 2). Выборочная проверка путевых листов показала, что все заместители председателя совнархоза продолжали использовать предоставляемые дежурные автомобили как персональные. Машины ежесуточно в утренние часы подавались ведомственным чинам на квартиры, а в служебное время обычно простаивали, ибо никто другой ими не пользовался. Диспетчерские службы отмечали в своих журналах только выход из гаража и возврат. В Министерстве путей сообщения СССР летом доля разъездов служебных автомобилей на дачи и в дома отдыха чиновников составила $44 \%$ пробега, зимой- 12\%. Например, в воскресенье 5 февраля 1961 г. три из четырех дежурных легковушки в среднем в течение 8 часов (или 90\% работы на линии) использовались именно для этой цели, пробежав 440 км (ГА РФ. Ф. 9477. Оп. 1. Д. 825. Л. 17-18). По воспоминаниям И. А. Андреевой, в их семье всех гостей на дачу в Архангельское привозили большой черный ЗИС свекра, члена Президиума Верховного Совета СССР, и черный же ЗИМ свекрови, директора ВИАлегпрома (Андреева 2009: 104).

Организация ведомственных крупных баз привела к бесконтрольности использования машин и способствовала возрождению практики закрепления их в персональное пользование за отдельными должностными лицами. В Положениях, разработанных для автобаз Ленгорисполкома и облисполкома, прямо предусматривалось, что заведующие отделами и начальники управлений могут пользоваться автомобилем для проезда к месту службы и возвращения с работы. Заместителям председателя и секретарям исполкомов предоставлялось право вызова машины в течение суток, включая выходные и праздники. В результате в автобазе Ленгорисполкома семь легковых авто «Волга» оказались закреплены за семью руководителями исполнительной власти города (ЦГА СПб. Ф. 9626. Оп. 1. Д. 137. Л. 10).

Наиболее крупные гаражи и авторемонтные мастерские находились в ведении ЦК компартий и Советов Министров союзных республик, обкомов, облисполкомов, горисполкомов, совнархозов. Все они, как правило, остались у своих владельцев. Так, Ленгорисполком из 14 гаражей, предусмотренных к передаче для общего пользования, фактически освободил к апрелю 1960 г. только три гаража на 115 машиномест, а Ленсовнархоз- 
один гараж на 40 машиномест (ЦГА СПб. Ф. 9626. Оп. 1. Д. 137. Л. 6). Сходным образом обстояли дела в Челябинске, Туле, Караганде, Перми и других городах. В итоге новые таксомоторные парки не создавались, городские и междугородные линии маршрутных такси увеличивались мало, прокатные базы оказывалось нечем укомплектовать. По Ленинграду к 1 апреля 1960 г. были переданы на пополнение таксомоторных парков только 35 машин, а пункты проката для граждан вовсе не были организованы (ЦГА СПб. Ф. 9626. Оп. 1. Д. 137. Л. 8).

Многие автомобили, передаваемые в автохозяйства, находились в технически неудовлетворительном состоянии, порою даже не на ходу. В Ленинграде к 25 апреля 1960 г. было выявлено восемь организаций, в которых машины разукомплектовывались, детали заменялись на изношенные, а также напрямую расхищались агрегаты, приборы и прочее оборудование. Так, например, жилищное управление Смольнинского района при передаче «Москвича-401» заменило в нем исправный двигатель с коробкой передач на непригодный к эксплуатации (ЦГА СПб. Ф. 9626. Оп. 1. Д. 137. Л. 18, 35).

По просьбам многих ЦК компартий союзных республик, работники, ранее пользовавшиеся персональными автомобилями, получили право приобретать высвобождающиеся машины с оплатой их стоимости в рассрочку до одного года, с уценкой с учетом их износа, по спискам, представленным исполкомами райсоветов. Оставшиеся машины, как правило, поступали в комиссионные магазины (в Ленинграде, например, они продавались в Апраксином дворе). При этом отмечались злоупотребления в определении их стоимости. Чиновники- члены соответствующих комиссий- занижали оценку и затем приобретали легковушки сами или рекомендовали знакомым. Только в трех областях Казахской ССР (АлмаАтинской, Карагандинской и Актюбинской) удалось выявить факты неправильной оценки 34 автомобилей, разница составила 260 тыс. руб. (ГА РФ. Ф. 9477. Оп. 1. Д. 538. Л. 448).

Слухи о перераспределении авто, принадлежавших ранее чиновникам, распространялись среди населения и будоражили умы. Так, членкорреспондент Академии наук СССР, химик-технолог Н.Н. Качалов ходатайствовал о разрешении поменять свою машину марки «Победа» (купленную в 1955 г. и имевшую пробег 91 тыс. километров) на «ЗИМ» в хорошем состоянии, ссылаясь на плохое состояние здоровья своей супруги- народной артистки СССР Е.И. Тиме: «почечная болезнь моей жены совершенно не допускает тряски при автомобильной езде» (ЦГА СПб. Ф. 7384. Оп. 37а. Д. 81. Л. 121). Исполком Ленгорсовета разрешил ему приобрести в личное пользование за наличный расчет без рассрочки легковой автомобиль «ЗИМ» из числа автомашин, переданных для продажи населению, приняв «Победу» на комиссию через продажи в магазин Ленспортторга. Удовлетворена была и просьба лауреата Ленинской премии, директора 
главной геофизической обсерватории М.И. Будыко: он купил автомобиль ГАЗ-12 в связи с «необходимостью осуществлять оперативное руководство подразделениями обсерватории» (ЦГА СПб. Ф. 7384. Оп. 37а. Д. 81. Л. 123). А вот И.А. Степанов- персональный пенсионер всесоюзного значения (член партии с 1914 г.) получил отказ под тем предлогом, что «старые списанные автомашины исполком Ленгорсовета не реализует» (ЦГА СПб. Ф. 7384. Оп. 37а. Д. 81. Л. 116). Отказали и В. А. Андрееву, всю жизнь проработавшему электромонтером и мечтавшему о «Москвиче», чтобы «в выходной день уехать куда-нибудь в наш прекрасный пригород, да еще с внучатами» (ЦГА СПб. Ф. 7384. Оп. 37а. Д. 81. Л. 128).

Поскольку передаче в общее пользование не подлежали автомобили специального назначения (медицинской помощи, для перевозки почты, аварийно-технической службы и иные), многие руководители, стремясь сохранить машины в своем ведении, перевели их в эту категорию. На 1 января 1960 г. в предприятиях и организациях Ленинграда было зарегистрировано 418 автомобилей специального назначения (без учета парка скорой и неотложной медпомощи и милиции). К 1 апреля их количество выросло до 624 (ЦГА СПб. Ф. 9626. Оп. 1. Д. 137. Л. 12). В целом по РСФСР в течение 1959 г. в категорию специальных были переведены более 2 тыс. автомобилей, в одном только Министерстве путей сообщения их число увеличилось на 580 единиц. Поэтому количество машин, подлежавших передаче в автохозяйства общего пользования по проверяемым Комиссией советского контроля ведомствам, уменьшилось с 46 тыс. в январе 1960 г. до 31,6 тыс. в мае. В целом по стране, по оценкам контролеров, такая практика уменьшила сумму экономии примерно на 180 млн руб. (ГА РФ. Ф. 9477. Оп. 1. Д. 538. Л. 446).

Абсолютное большинство легковых автомобилей, переведенных в категорию специальных, не имели особого оборудования. Ленинградский комитет радио и телевидения ограничился нанесением на борт шести машин («ЗИМ-12», «Волга» и «Победа») надписи «Радио и телевидение». А управление книжной торговли оставило себе «Москвич-407», установив на него рупоры громкоговорителя. Начальник Ленинградского управления курортов, санаториев и домов отдыха Карелина, не желая расстаться с автомобилем «Москвич-401», 29 января 1960 г. поручила сделать на нем надпись «Почтово-оперативная», 21 марта- «Санитарная», а 24 и 30 марта предписала Дирекции дома отдыха переделать надпись на «Медицинская служба» (ЦГА СПб. Ф. 9626. Оп. 1. Д. 137. Л. 12, 15). Использовались все эти машины по личным надобностям аппаратчиков. В ходе проведенного в начале апреля 1961 г. ленинградской Госавтоинспекцией рейда удалось выявить 259 таких автомобилей. Например, «Победа» с надписью «Медслужба» перевозила заместителя начальника Городского аптечного управления на службу, «ЗИМ-12» вез секретаря парторганизации Ленгорздравотдела, а «ГАЗ-69» перевозил доски на дачу начальника локомотивного депо Октябрьской железной дороги (ЦГА СПб. Ф. 9626. Оп. 1. Д. 137. Л. 14). 
В дни спортивных соревнований подобная практика приобретала массовый характер. По неполным данным, для поездки на футбольный стадион им. С.М. Кирова в Ленинграде, 13 мая 1960 г. было задействовано около 100 единиц служебных машин, автомобилей специального назначения и ведомственных автобусов, а 20 мая - 162 единицы. В марте 1960 г. в Свердловске к центральному стадиону на хоккейный матч прибыли зрители на 128 специальных автомобилях (ГА РФ. Ф. 9477. Оп. 1. Д. 538. Л. 446).

Как выяснила Комиссия государственного контроля, к 1 апреля 1960 г. в проверенных краях, областях, республиках РСФСР из 12402 машин, подлежавших передаче в автохозяйства общего пользования, по-прежнему находились в ведомственном пользовании 4113 , или 33,5\% (ГА РФ. Ф. 9477. Оп. 1. Д. 538. Л. 445). По Ленинграду и области из 3376 машин оказались переданы всего 1488 единиц (44\%) (ЦГА СПб. Ф. 9626. Оп. 1. Д. 137. Л. 4). Повторная проверка в апреле 1961 г. показала, что по-прежнему у подъездов зданий совнархозов и исполкомов бесцельно простаивали часами вереницы служебных авто. В начале и в конце рабочего дня, как правило, вызвать машину из гаража было невозможно, так как все они занимались перевозкой аппаратчиков. Шоферов зачисляли на иные должности, продолжая оплачивать их труд за счет производства. На Ижорском заводе, например, три водителя числились машинистами грузоподъемных кранов, на их содержание в 1960-1961 гг. было израсходовано 6100 руб. (ЦГА СПб. Ф. 9626. Оп. 1. Д. 137. Л. 54).

По мнению сына первого секретаря, С.Н. Хрущева, эффект, как и от других его кампаний по борьбе с привилегиями (денежными пакетами, пенсиями военнослужащих, северными надбавками), оказался невелик. Немногое, что удалось - это слегка сократить парк персональных машин, пересадить часть чиновников с «Чаек» ручной сборки на более дешевые «Волги», хотя министры, апеллируя к соображениям престижа, отстояли свое право на «Чайки». Громоздкими «ЗИЛами» стали пользоваться не все члены Президиума ЦК, а только три высших лица в государстве: первый секретарь ЦК, Председатель правительства и Председатель Президиума Верховного Совета (Хрущев 2010b: 16). Но, как отмечал сын руководителя советского государства:

большинство населения страны обижалось, что «недодают», а меньшинство возмущалось, что «отобрали». Министрам, а также, что особенно важно, их женам, «Волги» с непривычки казались тесными, неудобными и абсолютно не престижными. Начальники, у которых вообще отобрали «персоналки», ворчали, что теперь они работать не могут: вызывают на срочное заседание, а если вовремя заявку на машину не подал, приходится ждать очереди, не в метро же ехать (Хрущев 2010a: 652).

«Лимузинная» кампания не прибавила популярности Н. С. Хрущеву в рядах номенклатуры и способствовала его отстранению от власти. 
Весьма показательно, что когда первый секретарь был отправлен в отставку, снижение его статуса мгновенно маркировалось посредством изменения категории предоставленного в его распоряжение автомобиля. На следующий день после судьбоносного для него Пленума ЦК КПСС 14 октября 1964 г.:

у ворот с самого утра без вызова застыла «Чайка», заменившая привычный «ЗИЛ». «Чайка» у ворот простояла недолго. В тот же день она исчезла так же незаметно, как и появилась, а еще через полчаса на ее месте оказалась «Волга»... кому-то из начальников вспомнились его неоднократные попытки упразднить или хотя бы сократить персональные автомобили... Передавали нам даже слова одного анонимного начальника: «Хотел нас на «Волги» пересадить? Пусть теперь сам попробует» (Хрущев 2010b: 102).

\section{«Восстановилась прежняя практика»}

Неудивительно, что со сменой власти все вернулось на круги своя. Очередные постановления Совета Министров СССР, направленные на упорядочение использования служебных и специальных автомобилей, принимались 31 мая 1973 г., 16 февраля 1981 г., 23 января 1988 г. Все они содержали один и тот же перечень мероприятий: передачу машин в автохозяйства общего пользования, сокращение расходов на содержание ведомственных авто, использование их без штатных водителей, нормализацию парка спецмашин. И заканчивались без особого результата. К 15 декабря 1973 г. в РСФСР было отчислено из ведомственных гаражей 6600 служебных автомобилей, расход на содержание которых достигал 22,8 млн руб. (ГА РФ. Ф. 5446. Оп. 108. Д. 1011. Л. 69). Однако проведенная в первом квартале 1978 г. проверка показала, что в большинстве министерств и ведомств восстановилась прежняя практика. Приведем два примера. По восемнадцати организациям Минмонтажспецстроя использовалось 87 машин вместо 67, их перепробеги за второе полугодие 1977 г. превысили один миллион километров, на что израсходовано было более 130 тыс. литров бензина. Автомобиль, обслуживавший заместителя начальника Главснаба БССР, в июле-декабре 1977 г. имел пробег в выходные дни более 6 тыс. километров (около $40 \%$ от общего), осуществлял поездки по республике без оформления командировочных, без указания маршрутов в путевых листах (ГА РФ. Ф. 9527. Оп. 1. Д. 5859. Л. 30, 32).

Стоит ли удивляться, что представители номенклатуры игнорировали соответствующие правительственные решения. Более того, с момента выхода постановления «О дополнительных мерах по упорядочению использования служебных и специальных легковых автомобилей» (16 февраля 1981 г.) к 1 января 1984 г. в учебных заведениях Министерства высшего и среднего образования, например, число таких машин увеличилось более, 
чем в полтора раза (до 1454 единиц), а на предприятиях Миннефтехимпрома - с 499 до 812 (ГА РФ. Ф. 9527. Оп. 1. Д. 8263. Л. 4, 18). На заседании Президиума Совета Министров СССР 17 июля 1979 г. обсуждался вопрос об установлении лимитов количества служебных машин. Многие выступавшие предлагали не менять устоявшийся порядок. Так, глава Минавтопрома В.Н. Поляков считал, что дальнейшее сокращение парка служебных и специальных авто затруднит оперативное решение вопросов и нарушит бесперебойную организацию производственно-хозяйственной деятельности (ГА РФ. Ф. 9527. Оп. 1. Д. 5859. Л. 76).

По данным корреспондента газеты «Неделя» И. Корчагиной, в середине 1980-х гг. в СССР потребности номенклатурных работников разных уровней обслуживали около 400 тыс. служебных машин и еще примерно 350 тыс. специальных. На содержание казенных легковушек государство тратило столько же, сколько на содержание всего городского пассажирского транспорта страны- автобусов, троллейбусов, трамваев и даже метро. Их обслуживали столько же водителей, сколько городские автобусы и такси (Корчагина 1988). В условиях «перестроечной» демократизации общественной жизни обсуждалась программа выделения каждому предприятию лимита на содержание служебных авто в размере 7635 руб. в год. Директору предполагалось оставить в пользование одну машину, а сэкономленные деньги (4634 руб.) использовать на выплату компенсаций тем, кто будет ездить по производственным делам на личном транспорте. При годовом пробеге 15 тыс. километров компенсация в месяц могла составить 197 или 150 руб., в зависимости от марки автомобиля. За вычетом затрат на бензин и обслуживание (из расчета 11 коп. с километра пробега) можно было получить не менее 30 руб. чистого «навара». Однако автовладельцы ни за что не соглашались использовать собственную машину для служебных поездок (Корчагина 1988).

\section{Заключение}

Согласно идее Жана Бодрийяра, все вещи в мире людей обладают социально-значимыми характеристиками. Соответственно потребность человека обладать вещью является потребностью заявить свое место в общественной иерархии. Автомобиль, с самого начала своего появления отягощенный «паразитарными функциями престижа, комфорта, бессознательной проекции», как нельзя лучше позволяет понять специфику советского социума посредством «системы вещей» (Бодрийяр 2001: 139).

Как заметил английский экономист Хиллель Тиктин, деньги, которые трудно потратить, не приносят особой пользы. Это утверждение, по его мнению, в полной мере можно было применить к СССР, где для большинства населения гораздо большую значимость, нежели деньги, имели экономия проведенного в очередях времени и доступ к распределительной 
системе (Tictin 1973:37). Ведомственное авто как раз и оказывалось необходимым атрибутом причастности к особому кругу допущенных к государственному распределению. Кроме того, в СССР приобретение и обслуживание личного автомобиля оказывалось сопряжено со значительными сложностями. В 1970 г. в Советском Союзе было выпущено 344 тыс. легковых машин. Согласно приказу Министерства автотранспорта и шоссейных дорог РСФСР, изданному 20 января 1969 г., к 1975 г. следовало построить 2500 станций технического обслуживания, стоянок на 147500 машиномест, 420 моечных пунктов (ГА РФ. Ф. 9527. Оп. 1. Д. 2348. Л. 17). Но даже эта скромная программа оказалась сорвана. Нередко обслуживать автомобиль оказывалось сложнее, чем приобрести (Твердюкова 2018). Все это не позволяло гражданам относиться к автомобилю как к обычному средству передвижения. В этой связи понятно категорическое нежелание чиновников даже низшего звена использовать личную автомашину для поездок по производственной необходимости.

По мнению В.В.Костикова, «спецобслуживание», порождающее «систему спецхолуйства», в нормально действующей, бездефицитной экономике не нужно (Костиков 1989: 15). Но представляется, что чрезвычайно важна роль автомобиля как маркера социальной стратификации. Даже в наши дни, когда личной машиной с водителем никого не удивишь, акценты сместились в сторону статусности авто и специальных номеров. Сегодня государственные закупки машин люксовых марок для чиновников регулярно становятся предметом громких разоблачений и вызывают справедливое негодование общественности. А для управленцев всех уровней попрежнему характерен взгляд на ведомственное авто как на свою собственность, что предопределяет широкое его использование в личных целях. Борьба с транспортными привилегиями госслужащих в России остается классическим примером попытки реализации политической утопии.

\section{Список сокращений}

ВИАлегпром- Всесоюзный институт ассортимента изделий легкой промышленности и культуры одежды.

ГА РФ- Государственный архив Российской Федерации.

РГАСПИ- Российский государственный архив социально-политической истории.

ЦГА СПб-Центральный государственный архив Санкт-Петербурга.

\section{Список источников}

ХХ съезд (1956) ХХ съезд Коммунистической партии Советского Союза: стеногр. отчет. Т. 1. М.: Госполитиздат.

Андреева И.А. (2009) Частная жизнь при социализме. Отчет советского обывателя. М.: НЛО. 
Бодрийяр Ж. (2001) Система вещей. М.: Рудомино.

Восленский М. (2005) Номенклатура. М.: Захаров.

Джилас М. (1961) Новый класс. Нью-Йорк: Фредерик А. Прегер.

Кондратьева Т. (2006) Кормить и править: о власти в России XVI-XX вв. М.: POCСПЭН.

Коновалов А.Б. (2005). Партийная номенклатура Кузбасса в годы «послевоенного сталинизма» и «оттепели» (1945-1964). Кемерово: СКИФ.

Кононенко Р. В. (2011) Автомобильность в России. М.: Вариант.

Коржихина Т.П., Фигатнер Ю.Ю (1993) Советская номенклатура: становление, механизмы действия. Вопросы истории, (7):25-38.

Корчагина И. (1988) Эксперимент, который не состоялся. Неделя, 15-21 февраля:4-5.

Костиков В. (1989) Блеск и нищета номенклатуры. М.: Правда.

Крыштановская О.В. (2005) Анатомия российской элиты. М.: Захаров.

Левин М. (1997) Номенклатура-Arcanum Imperii: (Технология управления против технологии управленцев). Т.И. Заславская (ред.) Куда идет Россия: Общее и особенное в современной России. М.: Интерцентр: 69-76.

Мирская М. Л. (2013) Автомобиль в советской культуре. М.: ВШЭ.

Пашин В. П., Свириденко Ю.П. (1998) Кадры коммунистической номенклатуры: методы подбора и воспитания. М.: ГАСБУ.

Фурсенко А. А. (ред.) (2008) Президиум ЦК КПСС. 1954-1964. Черновые протокольные записи заседаний: Стенограммы. Постановления. Т. 3: Постановления. 19591964. М.: РОССПЭН.

Сигельбаум Л. (2011) Машины для товарищей: биография советского автомобиля. М.: РОССПЭН.

Соболев Г.Л. (2012) Блокада Ленинграда: постижение правды. Новейшая история России, (2): 72-87.

Твердюкова Е. Д. (2018) Антисервис: личный автомобиль и его техническое обслуживание в СССР (1960-е-1980-е годы). Новейшая история России, 8 (3): 659-678.

Хрущев С.Н. (2010а) Трилогия об отще: Ч. 1: Реформатор. М.: Время.

Хрущев С.Н. (2010b) Трилогия об отце: Ч. 3: Пенсионер союзного значения. М.: Время.

Шалак А. В. (2013) О социальном статусе советских руководящих кадров в 19401950 -е гг. (на примере Восточной Сибири). Известия Иркутской государственной экономической академии, (3): 164-170.

Siegelbaum L.H. (2009) On the Side: Car Culture in the USSR, 1960s-1980s. Technology and Culture, 50 (1): 1-22.

Tictin H.H. (1973) Towards a Political Economy of the USSR. Critique, (1): 20-41. 
Elena Tverdyukova

\title{
CAMPAignS to REgULARIZE THE USE BY OfFICIAL CARS IN THE USSR (FROM THE 1950'S TO THE 1980'S)
}

\begin{abstract}
This article examimes efforts to regularize the use of official cars in the USSR during a campaign against the privelages of the Soviet 'ruling class', which is a topic not previously covered by social research. The research is based on archival documents, laws and regulations, materials from periodicals, and sources of personal origin. The research covers the period of the late 1950 's, when party debate began over the nomenklatura's increasingly visible access to privelages and their usage of state vehicles for personal use. On one hand, this led to the expansion of the state vehicle fleet, on the other, there was the demand to construct a society of social fairness. Krushchev's campaign worsened his popularity among the high nomenklatura and hastened his removal from power. In the following years, all attempts to reform the system of access to state vehicles were left to the Transport Department. Its main remit was adding vehicles to fleet pool whole reducing expenses for maintaining this pool. Not one of these reforms brought substantial results; examining the case of this campaign to regulate car use tells us much about Soviet motorization. Car access gained the symbolic function of prestige and was monopolized by a privelaged minority; in other words, it served as an element of social stratification. In this light, the reform of the automobile fleet was doomed to failure and was a classic example of attempting to realise political utopianism by achieving social equality.
\end{abstract}

Keywords: USSR, ruling class, soviet nomenklatura, privileges, car, reforms

DOI: $10.17323 / 727-0634-2019-17-2-253-266$

\section{References}

Andreeva I. A. (2009) Chastnaya zhizn' pri sotsializme. Otchet sovetskogo obyvatelya [Private Life during Socialism. A Report from a Soviet Inhabitant]. Moscow: NLO.

Baudrillard J. (2001) Sistema veshhej [The System of Objects]. Moscow: Rudomino.

Dilas M. (1961) Novyy klass [The New Class]. New York: Frederik A. Preger.

Fursenko A. A. (ed.) (2008) Prezidium TsK KPSS. 1954-1964. Chernovye protokol'nye zapisi zasedaniy: Stenogrammy. Postanovleniya. T. 3: Postanovleniya. 1959-1964 [Presidium of Central Committee of CPSU. 1954-1964. Draft Protocolary Records of the Meeting: Shorthand Records. Decisions. Vol. 3: Decisions. 1959-1964]. Moscow: ROSSPEN.

Khrushchev S. N. (2010a) Trilogiya ob ottse: Ch. 1: Reformator [Trilogy about a Father: Part 1: Reformer]. Moscow: Vremya.

Elena D. Tverdyukova - doctor in history, associate professor, professor of the department of Modern history of Russia, Institute of history, Saint-Petersburg State University, Saint-Petersburg, Russian Federation. Email: e.tverdyukova@spbu.ru 
Khrushchev S.N. (2010b) Trilogiya ob ottse: Ch. 3: Pensioner soyuznogo znacheniya [Trilogy about a Father: Part 3: Pensioner of the allied value]. Moscow: Vremya.

Kondrat'eva T. (2006) Kormit' i pravit': o vlasti v Rossii XVI-XX vv. [To Feed and Govern: Power in the Russia from the $16^{\text {th }}$ to $20^{\text {th }}$ century]. Moscow: ROSSPEN.

Kononenko R. V. (2011) Avtomobil'nost'v Rossii [Automobility in Russia]. Moscow: Variant.

Konovalov A. B. (2005) Partiynaya nomenklatura Kuzbassa v gody 'poslevoennogo stalinizma' $i$ 'ottepeli' (1945-1964) [The Party Nomenklatura of Kuzbuss in the Years of 'Post-war Stalinism' and the 'Thaw' (1945-1964)]. Kemerovo: SKIF.

Korchagina I. (1988) Eksperiment, kotoryy ne sostoyalsya [The Experiment that did not Take Place]. Nedelya [The Week], February 15-21:4-5.

Korzhikhina T.P., Figatner Yu.Yu (1993) Sovetskaya nomenklatura: stanovlenie, mekhanizmy deystviya [The Soviet Nomenklatura: Becoming, Mechanisms of Action]. Voprosy istorii [Questions of History], (7):25-38.

Kostikov V. (1989) Blesk i nishcheta nomenklatury [The Brilliance and Poverty of the Nomenklatura]. Moscow: Pravda.

Kryshtanovskaya O. V. (2005) Anatomiya rossiyskoy elity [An Anatomy of the Russian Elite]. Moscow: Zakharov.

Levin M. (1997) Nomenklatura - Arcanum Imperii: (Tekhnologiya upravleniya protiv tekhnologii upravlentsev) [Nomenclature- Arcanum Imperii: (Management Technology Against Technology of Managers)]. In: T.I. Zaslavskaya (ed.) Kuda idet Rossiya: Obshchee i osobennoe v sovremennom razvitii [Where is Russia Going: The Common and the Special in Modern Development]. Moscow: Intertsentr:69-76.

Mirskaya M.L. (2013) Avtomobil'v sovetskoy kul'ture [The Automobile in Soviet Culture]. Moscow: VShE.

Pashin V.P., Sviridenko Yu.P. (1998) Kadry kommunisticheskoy nomenklatury: metody podbora $i$ vospitaniya [The Workforce of the Communist Nomenklatura: Methods of Selection and Education]. Moscow: GASBU.

Shalak A.V. (2013) O sotsial'nom statuse sovetskikh rukovodyashchikh kadrov v 1940-1950-e gg. (na primere Vostochnoy Sibiri) [The Social Status of Soviet Leading Cadres in 1940-1950s (on the Example of East Siberia)]. Izvestiya Irkutskoy gosudarstvennoy ekonomicheskoy akademii [Baikal Research Journal], (3): 164-170.

Siegelbaum L. (2011) Mashiny dlya tovarishchey: biografiya sovetskogo avtomobilya [Cars for Comrades: A Biography of the Soviet Automobiles]. Moscow: ROSSPEN.

Siegelbaum L. (2009) On the Side: Car Culture in the USSR, 1960s-1980s. Technology and Culture, 50 (1): 1-22.

Sobolev G.L. (2012) Blokada Leningrada: postizhenie pravdy [The Blockade of Leningrad: Establishing the Truth]. Noveyshaya istoriya Rossii [The Modern History of Russia], (2): 72-87.

Tictin H.H. (1973) Towards a Political Economy of the USSR. Critique, (1): 20-41.

Tverdyukova E.D. (2018) Antiservis: lichnyy avtomobil' i ego tekhnicheskoe obsluzhivanie v SSSR (1960-e-1980-e gody) [Anti-service: The Personal Automobile and Its Maintenance in the USSR (1960s-1980s)]. Noveyshaya istoriya Rossii [The Modern History of Russia], 8 (3): 659-678.

Voslenskiy M. (2005) Nomenklatura [Nomenklatura]. Moscow: Zakharov.

XX s"ezd (1956) XX s"ezd Kommunisticheskoy partii Sovetskogo Soyuza: stenogr. otchet. [The Twentieth Congress of the Communist Party of the Soviet Union]. Vol. 1, Moscow: Gospolitizdat. 